\title{
Medium-term temporal stability of the helminth component community structure in bank voles (Clethrionomys glareolus) from the Mazury Lake District region of Poland
}

\author{
A. BAJER ${ }^{1}$, J. M. BEHNKE ${ }^{2 *}$, A. PAWEŁCZYK ${ }^{1}$, K. KULIŚ ${ }^{1}$, M. J. SEREDA ${ }^{1} \dagger$ and E. SIŃSKI \\ ${ }^{1}$ Department of Parasitology, Institute of Zoology, University of Warszawa, ul. Miecznikowa 1, 02-096 Warszawa, Poland \\ ${ }^{2}$ School of Biology, University of Nottingham, University Park, Nottingham NG7 2RD, UK
}

(Received 26 March 2004; revised 14 Fuly 2004; accepted 14 fuly 2004)

S UMMAR Y

The structure of helminth communities in wild rodents is subject to seasonal variation, and is dependent on host age within years. Although between-year variation has been monitored, seldom has it been assessed rigorously by appropriate multifactorial analysis with potentially confounding factors taken into account. In this study we tested the null hypothesis that despite seasonal, host age and sex effects, helminth communities should show relative stability between years. Over a period of 3 years (1998-2000) we sampled bank vole (Clethrionomys glareolus) populations (total $n=250$ ) at 2 points in the year: in spring, at the start of the breeding season, and in autumn, after the cessation of breeding. In spite of seasonal differences and strong age effects, the between-year effects were surprisingly small. Measures of component community structure (BergerParker dominance index, the dominant species, S. petrusewiczi) did not vary, or varied only slightly from year to year. The majority of measures of infracommunity structure [Brillouin's index of diversity, prevalence of all helminths combined, prevalence and abundance of $H$. mixtum (the most prevalent helminth), mean species richness] did not differ significantly between years when other factors such as age, sex and seasonal variation had been taken into account. Some between-year variations were found (at the component community level, Simpson's index of diversity; at the infracommunity level, prevalence and abundance of $S$. petrusewiczi and abundance of all helminths combined), but even these were modest in comparison to seasonal and age differences, and were primarily attributable to $S$. petrusewiczi. We conclude that despite dynamic within-year fluctuations, helminth communities in bank voles in this region of Poland show relative stability across years. The sporadic occurrence of individual platyhelminths at low prevalence, makes little difference to the overall structure, which is largely maintained by the key roles played by the dominant intestinal nematodes of bank voles and the rarer species collectively.

Key words: bank vole, Clethrionomys glareolus, helminths, nematodes, cestodes, component community.

\section{INTRODUCTION}

The helminth fauna of wild rodents was documented in various European countries, throughout the last century (Elton et al. 1931; Furmaga, 1957; Tenora, 1967). After initial mainly descriptive studies (Żarnowski, 1955; Soltys, 1957; Sharpe, 1964) attention focused on the structure of helminth communities and the factors that regulate them (Lewis, 1968; Haukisalmi \& Henttonen, 1993). In eastern Europe extensive studies on rodent helminth communities were first conducted by Kisielewska and her collaborators in Poland in the 1950-1960s, concentrating on the dominant woodland species the bank vole Clethrionomys glareolus (Kisielewska, $1970 a, b, c$ ). These data are valuable in so far as they illustrate the

* Corresponding author: School of Biology, University of Nottingham, University Park, Nottingham NG7 2RD, UK. Tel: +44 (0) 1159513208 . Fax: +44 (0) 1159513251. E-mail: jerzy.behnke@nottingham.ac.uk $\uparrow$ Current address: Department of Molecular Parasitology, Institute for Biology, Humboldt University Berlin, Philippstrasse. 13, 10115 Berlin, Germany. basic pattern of changes in parasite prevalence, abundance and species composition with respect to seasons, years, spatial distribution of hosts and host age, but not having been subjected to multifactorial analyses they lack conviction with respect to the relative importance of the factors that were assessed.

Moreover, these initial studies in Poland were followed by taxonomic revision of many of the helminths involved (Tenora \& Meszaros, 1975; Wiger, Barus \& Tenora, 1978; Genov \& Yanchev, 1981; Haukisalmi \& Tenora, 1993) and consequently it is not always easy to interpret the earlier findings in the light of our current understanding of the helminth fauna of $C$. glareolus. There have been few relevant studies in recent years in Poland, but encouraged by current progress in the understanding of rodent helminth communities in Finland (Haukisalmi \& Henttonen, 2000), the Czech Republic and Slovakia (Tenora \& Stanek, 1995), we initiated a long-term programme to re-examine parasite component communities in wild rodents in Poland, in the Mazury Lake District region in the north-east of the country (Behnke et al. 2001). 
Information on seasonal fluctuations in the helminth fauna of European wild rodents is plentiful in the literature and is mostly based on wood mice Apodemus sylvaticus in the UK and Eire (Lewis, 1968; Langley \& Fairley, 1982; O’Sullivan, Smal \& Fairly, 1984; Abu-Madi et al. 2000) and the bank vole Clethrionomys glareolus in Scandinavia (Tenora, Wiger \& Barus, 1979; Haukisalmi, Henttonen \& Tenora, 1988). Seasonal changes in helminth component communities in bank voles were also identified as one of the most important determinants of variation in Kisielewska's (1970a) studies in Białowieża National Park in Poland. Seasonal patterns are likely to depend on local climatic conditions, which vary markedly across Europe. Since the transmission of parasites is dependent on local conditions that influence the survival and dispersal of invasive stages, we might expect differences in the extent and pattern of seasonal influences on helminth communities in different climatic zones in Europe.

The Mazury Lake District in Poland is covered by semi-natural managed forests, rich in plant and animal species, and characterized by long and severe winters, typically with temperatures below zero and deep snow cover. Winter begins usually in November and lasts until the end of March. The movement of wild rodents, including foraging, is therefore restricted during this season and parasite transmission probably reduced accordingly. The severe winter conditions also affect the survival of rodents and, as an example, in the winter of 2002/03 the ground was frozen to a depth of 1 meter for 3 months. Rodent populations crashed during this particular winter to such a degree that in May, with 300 traps in the field for 5 consecutive nights, we were unsuccessful in catching any rodents (unpublished observations). Under these specific climatic conditions we can expect different seasonal patterns to those described in wild rodents in Western Europe. Moreover, since the exact climatic conditions differ from year to year in Europe, a complete picture of the seasonal changes cannot be obtained through observations from a single cycle of seasons, yet longer-term studies are infrequent in the literature (but see Begon et al. 1999, 2003; Hazel et al. 2000 for long-term studies on viral transmission in wild rodents). Several have followed helminth populations for 3-4 years (Tenora \& Zejda, 1974; Tenora et al. 1979; Montgomery \& Montgomery, 1988, 1989, 1990), some for periods of 5-7 years (Kisielewska, 1970a) but in this context research on the vole populations in Finland is unique in that both host and parasite populations were monitored for periods of 8 to 17 years (Haukisalmi et al. 1988; Haukisalmi \& Henttonen, 2000).

In an earlier paper we found significant differences in helminth communities of bank voles from three semi-isolated, but ecologically comparable sites in the Mazury region of Poland (Behnke et al. 2001).
Where quantitative data permitted, we also evaluated for each species, and for higher taxa, the relative contribution of host age and sex. Exploiting data from one of our sites, we now focus on the betweenyear variation in helminth community structure. Since accurate data can only be obtained by culling animals, we restricted sampling to two seasons: spring (April-first half of June) at the start of the breeding period, when the population mainly comprises over-wintering adult voles, and autumn (second half of September), when the population size is always bigger and comprises mostly animals born in the current calendar year. We test the null hypothesis that the composition of helminth component communities of the bank vole $C$. glareolus does not differ significantly between years with season of study, host age and sex taken into account.

\section{MATERIALS AND METHODS}

\section{Study sites}

Our study site was located in Mazury in the north eastern corner of Poland, east of the nature reserve surrounding Lake Łuknajno, and north of Lake Śniardwy (long. 21 $39 \cdot 6^{\prime}$, lat. $53^{\circ} 47 \cdot 7^{\prime}$, Leśnictwo Luknajno) and about $5 \mathrm{~km}$ east of the town of Mikołajki. A full description of this site was provided in Bajer et al. (2001) and Behnke et al. (2001). Essentially it comprised a mature woodland with Scots pine (Pinus sylvestris) and silver birch (Betula verucosa) as the dominant trees but contained patches of dense Norway spruce (Picea abies), occasional oaks (Quercus robur), and common alders (Alnus glutinosa).

\section{Collection of voles}

Rodents were caught live in locally constructed wooden traps, with a small metal platform internally which when triggered released a metal door. Approximately 100 traps were used in total. These were set out at $20 \mathrm{~m}$ intervals in parallel lines, $10 \mathrm{~m}$ either side of tracks running through the site and 2 traps were placed within 2-3 m of one another at each point. Trapping sessions were conducted monthly in spring, summer and autumn, as indicated in Table 2 and each lasted 4 days with traps being inspected in the early morning and just before dusk. Fresh traps replaced any traps containing animals at each inspection and the animals were brought to the University of Warszawa's field station at Urwitałt. The majority of animals were examined alive (for studies on ecto- and haemoparasites and data are presented elsewhere) and then released, but the numbers of voles caught provided a relative measure of population density over the spring to autumn period. Since numbers caught could not be accurately related to land surface area, we consider these data to reflect relative population density. Voles 
trapped in April, May and first half of June were autopsied, the data were pooled from no more than 2 trapping sessions per annum separated by a maximum period of 3 weeks, because of low population densities in the spring (see Table 2) and are referred to as spring samples. Voles caught in the second half of September were autopsied and are referred to as autumn samples.

\section{Sampling of hosts}

At the field station, animals were identified, culled, weighed (to the nearest $0 \cdot 1 \mathrm{~g}$ ), sexed and relevant morphometric data were recorded (see below). Finally, the entire alimentary tract was removed, and incubated in fine netting suspended in a beaker containing Hanks' saline at $37^{\circ} \mathrm{C}$ for $2 \mathrm{~h}$. The livers, lungs and body cavity were inspected for helminths.

Three age classes were established primarily on the basis of the combined dry weight of the eye lenses of each animal (Morris, 1972) as follows: juveniles (lens weight $=3-5 \mathrm{mg})$, young adult $(5 \cdot 1-5 \cdot 9 \mathrm{mg})$, mature adults $(>5.9 \mathrm{mg})$. These categories correspond approximately to voles $<63,63-100$ and $>100$ days old (Kozakiewicz, 1976). However, adjustments were made, particularly at the limits of each category, using other morphometric measurements which included the following parameters: visual assessment of maturity at capture (juvenile/adult), externally apparent testes (scrotal/non scrotal), pregnancy and lactation, head length, head width, nose to anal length, tail length and foot length. All age-related factors showed the predicted increase from age class 1 through to age class 3 (data not shown but see Behnke et al. (2001) for details of approach adopted).

\section{Measures of community structure}

Following Kennedy \& Hartvigsen (2000), measures of component community structure were total number of helminth species, the Berger-Parker Dominance Index and Simpson's Index of Diversity [unbiased as $\left(1-\Sigma \mathrm{p}_{\mathrm{i}}{ }^{2}\right) \times(\mathrm{n} / \mathrm{n}-1)$, where $\mathrm{n}=$ total number of helminths in the sample (Washington, 1984) for each year in turn]. Infracommunity structure was assessed by mean number of helminth species per vole, maximum number of helminths and species density distribution across the sample, mean number of helminth individuals per vole, mean Brillouin's Index per vole (infected and uninfected), maximum Brillouin's Index, mean abundance and prevalence of individual species.

\section{Statistical analysis}

The frequency distribution of infracommunity species richness was tested for goodness of fit to the positive binomial distribution (assumption of the null model is a regular distribution), the Poisson distribution (assumption of the null model is a random distribution), the negative binomial model (assumption of the null model is an aggregated distribution) and the null model of Janovy et al. (1995) (assumption of the null model is that, in the absence of associations and interactions between species, the frequency distribution of infracommunity species richness is predicted by prevalence values of all the species comprising the component community). All distributions were tested for goodness of fit by $\chi^{2}$.

Prevalence data (percentage of animals infected) are shown with $95 \%$ confidence limits, calculated as described by Rohlf \& Sokal (1995). Prevalence was analysed by maximum likelihood techniques based on log-linear analysis of contingency tables using the software package Statgraphics Version 7. Beginning with the most complex model, involving all possible main effects and interactions, those combinations, which did not contribute significantly to explaining variation in the data, were eliminated in a stepwise fashion beginning with the highest-level interaction. A minimum sufficient model was then obtained, for which the likelihood ratio of $\chi^{2}$ was not significant, indicating that the model was sufficient in explaining the data. The statistical analysis is presented in an abbreviated format in the legends, where significant interaction terms are given alongside relevant figs, but it is important to remember that these represent tests of the individual terms in the minimum sufficient model simplified from the full factorial model that initially comprised 4 factors (year, season, age and sex) and the infected/uninfected factor.

Summary figures for parasite abundance are expressed either as arithmetic means \pm S.E.M. or, where distribution demanded, as means of $\log 10(x+1) \pm$ S.E.M. transformed data (corresponding to geometric means). Where relevant, the latter are also given as back-transformed values. These means reflect the abundance of infection as defined by Margolis et al. (1982) and Bush et al. (1997) and include all subjects within the specified group, infected and not infected, for which relevant data were available. The degree of aggregation in the data was calculated by the Index of Discrepancy $(D)$ as described by Poulin (1993) (a value of 0 indicates an even distribution of counts across all hosts and a value of 1 indicates all parasites aggregated in a single host) and the Index of Dispersion ( $I$, variance to mean ratio, where values $>1$ indicate overdispersed data). Frequency distributions of individual species were also tested for goodness of fit to negative binomial, positive binomial and Poisson models by $\chi^{2}$ as described by Elliott (1977) and the negative binomial exponent $k$ is given as appropriate.

Parasite abundance was analysed by GLIM (a statistical system for generalized linear interactive modelling; GLIM 4, PC version Royal Statistical Society, 1993 (Crawley, 1993; Wilson \& Grenfell, 1997) as described previously (Behnke et al. 1999), 
Table 1. The structure of the sampled bank vole population by season and year of study, and age and sex of host

\begin{tabular}{|c|c|c|c|c|c|c|c|}
\hline \multirow[b]{2}{*}{ Year } & \multirow[b]{2}{*}{ Season } & \multicolumn{3}{|c|}{ Age class } & \multicolumn{2}{|l|}{ Sex } & \multirow[b]{2}{*}{ Totals } \\
\hline & & 1 & 2 & 3 & Male & Female & \\
\hline \multirow[t]{2}{*}{1998} & Spring & 11 & 0 & 17 & 16 & 12 & 28 \\
\hline & Autumn & 7 & 11 & 11 & 15 & 14 & 29 \\
\hline \multirow[t]{2}{*}{1999} & Spring & 3 & 0 & 15 & 7 & 11 & 18 \\
\hline & Autumn & 21 & 48 & 31 & 50 & 50 & 100 \\
\hline \multirow[t]{2}{*}{2000} & Spring & 0 & 0 & 3 & 0 & 3 & 3 \\
\hline & Autumn & 31 & 34 & 7 & 37 & 35 & 72 \\
\hline Totals & & 73 & 93 & 84 & 125 & 125 & 250 \\
\hline
\end{tabular}

using models with negative binomial error structures (in which case arithmetic means are presented) or, if these could not be fitted, using models with normal errors after normalization of the data by $\log 10$ $(\mathrm{x}+1)$ transformation (in which case means of $\log 10(x+1)$ are presented). Year (3 levels, 1998, 1999 and 2000), season (2 levels, spring and autumn), host age (3 levels, age classes 1, 2 and 3 ) and host sex (2 levels, males and females) were entered as factors. We began in all cases with the full factorial models, including all main effects and interactions, and then progressively simplified them by deletion of terms, beginning with the highest order interactions, and progressing to the main effects. Three-way interactions were first deleted to register the change in deviance and then reinstated in turn until all had been evaluated. All 3-way interactions were then removed, and the procedure was repeated for 2-way interactions and for the main effects. For models with negative binomial errors the change in deviance is divided by the scale parameter to give $\chi^{2}$, whereas for models with normal errors the change in deviance is divided by the scale parameter and the result divided by the change in degrees of freedom (D.F.) following each deletion, to give a variance ratio, $F$. Finally, minimum sufficient models were fitted, entering only the significant terms, and the residuals from these were checked for approximately negative binomial or normal distribution as appropriate.

\section{RESULTS}

\section{Clethrionomys glareolus}

A total of 250 bank voles were sampled across 3 years. The structure of the sampled population by host sex, age, year of study is summarized in Table 1. The two sexes were equally represented in the total sample but there were marked differences in the numbers of voles caught during the various trapping sessions (Minimum sufficient log-linear model, year $\times$ season $\times$ age interaction $\chi^{2}=9 \cdot 8$, D.F. $\left.4, P=0 \cdot 04\right)$. Vole populations were always lower in spring, and in some
Table 2. Changes in the relative population density of Clethrionomys glareolus in the study site during 1998-2000

\begin{tabular}{lccc}
\hline \hline & \multicolumn{3}{c}{ Relative population density* } \\
\cline { 2 - 4 } Month & 1998 & 1999 & 2000 \\
\hline April & $10 \cdot 2$ & $7 \cdot 6 \dagger$ & $\mathrm{N} . \mathrm{D}$. \\
May & $1 \cdot 1 \dagger$ & $4 \cdot 1 \dagger$ & $2 \cdot 2 \dagger$ \\
June & $14 \cdot 4 \dagger$ & $\mathrm{N} . \mathrm{D}$. & $17 \cdot 2 \dagger$ \\
July & $13 \cdot 4$ & $52 \cdot 3$ & $\mathrm{~N} . \mathrm{D}$. \\
August & $34 \cdot 1$ & $85 \cdot 0$ & $27 \cdot 2$ \\
September & $44 \cdot 5 \dagger$ & $188 \cdot 3 \dagger$ & $65 \cdot 9 \dagger$ \\
October & $33 \cdot 5$ & $\mathrm{~N} . \mathrm{D}$. & $\mathrm{N} . \mathrm{D}$. \\
\hline \hline
\end{tabular}

*Population density was calculated as the number of rodents trapped, divided by trap hours $\times$ trap number $\times$ $10^{-4}$.

N.D., Not done.

†Animals caught in these months were autopsied to provide spring and autumn samples respectively.

years extremely scarce (e.g. 1998). 1999 was a peak bank vole year in autumn but even so vole densities were very low in May, as shown in Table 2. The sample sizes for voles of different ages also differed significantly, and particularly in spring when the population comprised over-wintered adults (age class 3 ) and newly recruited juveniles (age class 1 ) but no voles from age class 2 .

\section{Measures of component community structure}

Total species richness and component species. Fifteen species of helminths were recorded in total, 5 nematodes, 9 cestodes and 1 digenean (Table 3) and 225 voles $(90 \%)$ carried at least 1 of these species. The heligmosomid species, $H$. mixtum was the most prevalent helminth $(82.4 \%)$, followed by $S$. petrusewiczi $(28 \cdot 8 \%)$ but all the other species were only sporadically represented, overall prevalence not exceeding $10 \%$. Therefore overall, H. mixtum can be considered a core species (prevalence $>50 \%$ ) and $S$. petrusewiczi the only component species $(10 \%)$ in this population of bank voles, although the prevalence of $C$. henttonen $i$ was only just less than 10-50\%. However, prevalence of particular species varied between years and in relation to host parameters, and some of the other species also showed prevalence rates above $10 \%$ in some subsets of the data.

Total species richness, dominant species, diversity and similarity indices by year. The total number of helminth species recorded at our study site in each of the 3 years is given in Table 4. Most species were recorded in 1999, which was a year of high bank vole population density and, accordingly, our sample size was the highest in that year. Similarly, the lowest total species richness was in 1998 when we trapped 
Table 3 . The prevalence ( $\%$ infected $\pm 95 \%$ confidence limits) of helminth taxa by year of study

\begin{tabular}{|c|c|c|c|c|c|}
\hline \multirow[b]{2}{*}{ Taxon } & \multirow[b]{2}{*}{ Species } & \multicolumn{4}{|l|}{ Year } \\
\hline & & 1998 & 1999 & 2000 & All years \\
\hline \multirow[t]{5}{*}{ Nematodes } & Heligmosomum mixtum & $78 \cdot 9 \pm 10 \cdot 6$ & $81 \cdot 4 \pm 7 \cdot 0$ & $86 \cdot 7 \pm 7 \cdot 7$ & $82 \cdot 4 \pm 4 \cdot 7$ \\
\hline & Syphacia petrusewiczi & $22 \cdot 8 \pm 10 \cdot 9$ & $41 \cdot 5 \pm 8 \cdot 9$ & $13 \cdot 3 \pm 7 \cdot 7$ & $28 \cdot 8 \pm 5 \cdot 6$ \\
\hline & Aspiculuris tetraptera & $3 \cdot 5 \pm 4 \cdot 8$ & 0 & $12 \cdot 0 \pm 7 \cdot 4$ & $4 \cdot 4 \pm 2 \cdot 5$ \\
\hline & Heligmosomoides glareoli & 0 & $3 \cdot 4 \pm 3 \cdot 3$ & $1 \cdot 3 \pm 2 \cdot 6$ & $2 \cdot 0 \pm 1 \cdot 7$ \\
\hline & Mastophorus muris & 0 & $2 \cdot 5 \pm 2 \cdot 8$ & $1 \cdot 3 \pm 2 \cdot 6$ & $1 \cdot 6 \pm 1 \cdot 6$ \\
\hline All nematodes & & $82 \cdot 5 \pm 9 \cdot 9$ & $88 \cdot 1 \pm 5 \cdot 8$ & $90 \cdot 7 \pm 6 \cdot 6$ & $87 \cdot 6 \pm 4 \cdot 1$ \\
\hline \multirow[t]{4}{*}{ Cestodes } & Catenotaenia henttoneni & $12 \cdot 3 \pm 8 \cdot 5$ & $6 \cdot 8 \pm 4 \cdot 5$ & $12 \cdot 0 \pm 7 \cdot 4$ & $9 \cdot 6 \pm 3 \cdot 7$ \\
\hline & Paranoplocephala omphalodes & $1 \cdot 8 \pm 3 \cdot 4$ & $5 \cdot 9 \pm 4 \cdot 3$ & $8 \cdot 0 \pm 6 \cdot 1$ & $5 \cdot 6 \pm 2 \cdot 9$ \\
\hline & Anoplocephaloides dentata & $3 \cdot 5 \pm 4 \cdot 8$ & $3 \cdot 4 \pm 3 \cdot 3$ & 0 & $2 \cdot 4 \pm 1 \cdot 9$ \\
\hline & Rodentolepis assymetrica & 0 & $0 \cdot 8 \pm 1 \cdot 7$ & 0 & $0 \cdot 4 \pm 0 \cdot 8$ \\
\hline \multirow[t]{6}{*}{ All adult cestodes } & & $17 \cdot 5 \pm 9 \cdot 9$ & $14 \cdot 4 \pm 6 \cdot 3$ & $18 \cdot 7 \pm 8 \cdot 8$ & $16 \cdot 4 \pm 4 \cdot 6$ \\
\hline & Taenia martis & 0 & $3 \cdot 4 \pm 3 \cdot 3$ & $9 \cdot 3 \pm 6 \cdot 6$ & $4 \cdot 4 \pm 2 \cdot 5$ \\
\hline & Taenia mustelae & 0 & $1 \cdot 7 \pm 2 \cdot 3$ & $1 \cdot 3 \pm 2 \cdot 6$ & $1 \cdot 2 \pm 1 \cdot 4$ \\
\hline & Taenia crassiceps & 0 & $1 \cdot 7 \pm 2 \cdot 3$ & 0 & $0 \cdot 8 \pm 1 \cdot 1$ \\
\hline & Cladotaenia globifera & $1 \cdot 8 \pm 3 \cdot 4$ & $2 \cdot 5 \pm 2 \cdot 8$ & 0 & $1 \cdot 6 \pm 1 \cdot 6$ \\
\hline & Mesocestoides sp. & 0 & $1 \cdot 7 \pm 2 \cdot 3$ & $1 \cdot 3 \pm 2 \cdot 6$ & $1 \cdot 2 \pm 1 \cdot 4$ \\
\hline All larval cestodes & & $1 \cdot 8 \pm 3 \cdot 4$ & $11 \cdot 0 \pm 5 \cdot 6$ & $12 \cdot 0 \pm 7 \cdot 4$ & $9 \cdot 2 \pm 3 \cdot 6$ \\
\hline All cestodes & & $19 \cdot 3 \pm 10 \cdot 2$ & $21 \cdot 2 \pm 7 \cdot 4$ & $30 \cdot 7 \pm 10 \cdot 4$ & $23 \cdot 6 \pm 5 \cdot 3$ \\
\hline Digenea & Plagiorchis sp. & $1 \cdot 8 \pm 3 \cdot 4$ & $0--$ & 0 & $0 \cdot 4 \pm 0 \cdot 8$ \\
\hline \multicolumn{2}{|c|}{ All helminths (nematodes and cestodes combined) } & $84 \cdot 2 \pm 9 \cdot 5$ & $92 \cdot 4 \pm 4 \cdot 8$ & $90 \cdot 7 \pm 6 \cdot 6$ & $90 \cdot 0 \pm 3 \cdot 7$ \\
\hline
\end{tabular}

Table 4. Measures of component community structure by year

\begin{tabular}{|c|c|c|c|}
\hline & \multicolumn{3}{|l|}{ Year } \\
\hline & 1998 & 1999 & 2000 \\
\hline $\begin{array}{l}\text { Total no. of helminth } \\
\text { species identified }\end{array}$ & 8 & 13 & 10 \\
\hline $\begin{array}{l}\text { Berger-Parker dominance } \\
\text { index }\end{array}$ & $0 \cdot 885$ & $0 \cdot 981$ & $0 \cdot 844$ \\
\hline Dominant species & S. petrusewiczi & S. petrusewiczi & S. petrusewiczi \\
\hline Simpson’s index & $0 \cdot 212$ & $0 \cdot 038$ & $0 \cdot 275$ \\
\hline \multicolumn{4}{|l|}{$\begin{array}{l}\text { Jacard's index of similarity } \\
\text { (Shared species) }\end{array}$} \\
\hline 1998 & - & $0 \cdot 4(6)$ & $0 \cdot 385(5)$ \\
\hline 1999 & $0 \cdot 4$ & - & $0 \cdot 643(9)$ \\
\hline
\end{tabular}

fewest animals. In terms of similarity (see Jacard's index of similarity; Table 4), 1999 and 2000 were closer to one another than 1998 to either, and major contributors to this difference were the larval cestodes. In 1998 only one species (Cladotaenia globifera) was recorded, whilst in 1999 five larval cestode species were identified and in 2000 three species. The Berger-Parker dominance index was very similar in 1998 and 2000, but exceptionally high in 1999, and in all 3 cases $S$. petrusewiczi was the dominant species at the component community level. In 1999, when worm burdens with $S$. petrusewiczi were extremely high (maximum recovery $=6130$ ) Simpson's index was correspondingly low, and not surprisingly other species, despite the highest total species richness in that year, did not contribute much to the index (Table 4).

\section{Measures of infracommunity structure}

Mean species richness. The overall mean number of species harboured per host (all voles combined) was $1 \cdot 46 \pm 0.052$ (variance to mean ratio $=0 \cdot 456$ ). Mean species richness did not vary significantly between seasons (spring $1 \cdot 37 \pm 0 \cdot 15$; autumn $1 \cdot 49 \pm 0 \cdot 05$; 4way ANOVA in GLIM with normal errors and year, season, host age and sex as factors, for main effect of season $F_{1,244}=0 \cdot 07, P=$ N.S.) nor between years $(1 \cdot 26 \pm 0 \cdot 12,1 \cdot 56 \pm 0 \cdot 07,1 \cdot 47 \pm 0 \cdot 09$, in 1998 , 1999 and 2000 respectively, 4-way ANOVA, for main effect of year $F_{2,24}=1 \cdot 83, P=$ N.S.) although the mean values reflect an upward drift with time. However, there was a significant change with age (4-way ANOVA, for main effect of age $F_{2,249}=5 \cdot 73$, $0 \cdot 005>P>0 \cdot 001)$. Voles in age class 1 had a lower 

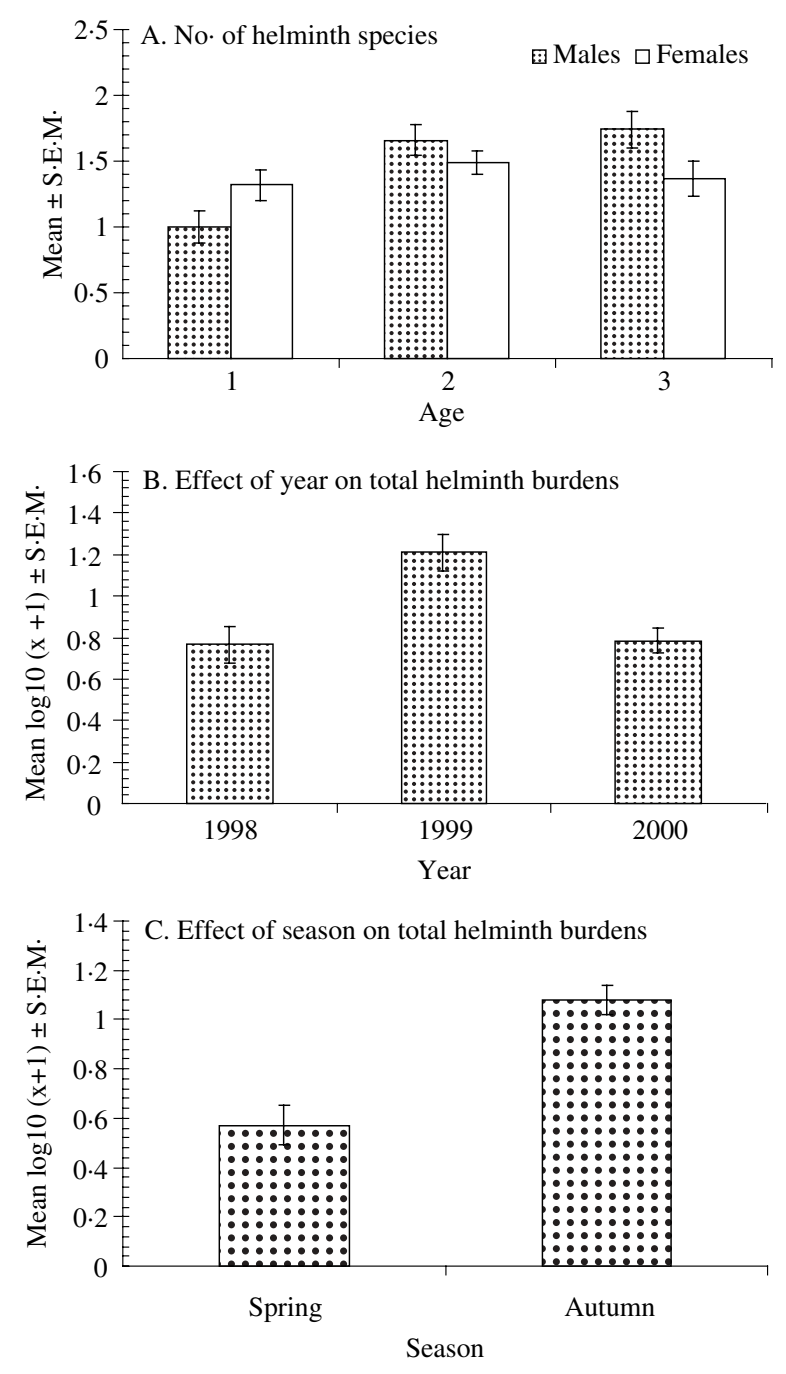

Fig. 1. The effect of host age and sex on mean species richness (A) and between year (B) and seasonal (C) variation in total helminth worm burdens.

value than those in age classes 2 and 3 , there being little difference between the values of the latter $(1 \cdot 19 \pm 0 \cdot 09,1 \cdot 58 \pm 0 \cdot 07,1 \cdot 57 \pm 0 \cdot 10$, in age classes 1 , 2 and 3 respectively). However, this age effect was confounded by a difference between the sexes in age-related change of mean species richness (4-way ANOVA, for interaction between sex and age $\left.F_{3,247}=2 \cdot 76,0 \cdot 05>P>0 \cdot 025\right)$ and as Fig. 1A shows mean species richness increased more consistently in males with age, but showed less change in females and even dropped marginally in the older animals. However, there was no overall difference between the sexes $($ males $=1 \cdot 5 \pm 0 \cdot 08$, females $=1 \cdot 4 \pm 0 \cdot 07)$.

\section{Measures of infracommunity diversity}

The maximum number of helminth species per vole ranged from 3 in 1999 to 4 in 2000 and 5 in 1998 (Fig. 3). The mean number of helminths harboured per vole varied markedly between years (Fig. 1B) as a result of very heavy infections with $S$. petrusewiczi
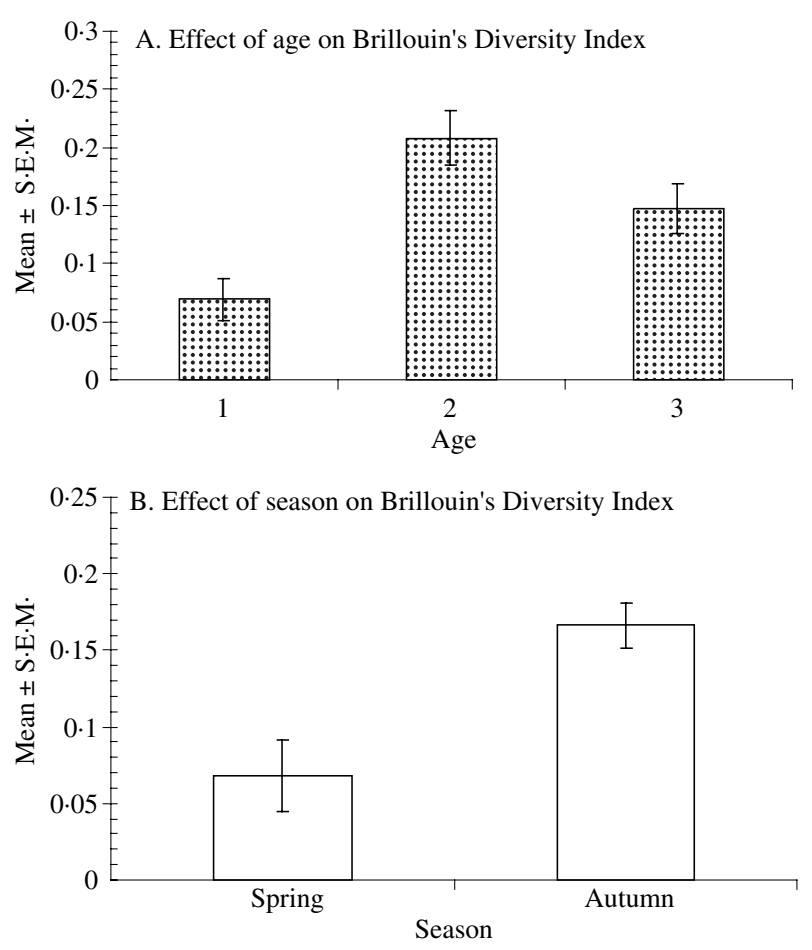

Fig. 2. The effect of age (A) and season (B) on Brillouin's Diversity Index.

recovered in 1999, and the difference between years was highly significant (4-way ANOVA on Log10 $(\mathrm{x}+1)$ transformed total worm burdens, with normal errors and year, season, host age and sex as factors, for main effect of year $\left.F_{2,249}=8 \cdot 77, P<0 \cdot 001\right)$. There was also a highly significant effect of season on total helminth worm burden (4-way ANOVA on Log10 $(\mathrm{x}+1)$ transformed total worm burdens, for main effect of season $F_{1,247}=15 \cdot 2, \quad P<0 \cdot 001$ ), and as Fig. $1 \mathrm{C}$ shows mean worm burdens were almost four times higher in autumn compared with spring (backtransformed means for spring $=2 \cdot 7$, autumn $=11 \cdot 1$ ).

Brillouin's diversity index did not vary significantly between the three years of the study $(0 \cdot 14 \pm 0 \cdot 03,0 \cdot 16 \pm 0 \cdot 02$ and $0 \cdot 13 \pm 0 \cdot 02$, in 1998, 1999 and 2000 respectively; 4-way ANOVA with year, season, sex and age as factors, for main effect of year $F_{2,245}=1 \cdot 13, P=$ N.S.) but there was a pronounced effect of age (4-way ANOVA, for main effect of age $\left.F_{2,248}=8 \cdot 1, P<0.001\right)$. As Fig. 2A shows, the lowest mean value was from the youngest voles, the peak value from age class 2 voles and then the value fell somewhat in older age class 3 voles. There was also an independent effect of season (4way ANOVA, for main effect of season $F_{1,247}=6 \cdot 24$, $0.025>P>0.01)$, which is illustrated in Fig. 2B. Quite clearly the greatest diversity of worm burdens was observed in autumn with the mean value being almost $2 \cdot 5$ times higher than in spring.

There was no overall difference in Brillouin's diversity index between the sexes (males $=0 \cdot 16 \pm 0 \cdot 02$, females $=0 \cdot 13 \pm 0 \cdot 02 ; 4$-way ANOVA for main effect 

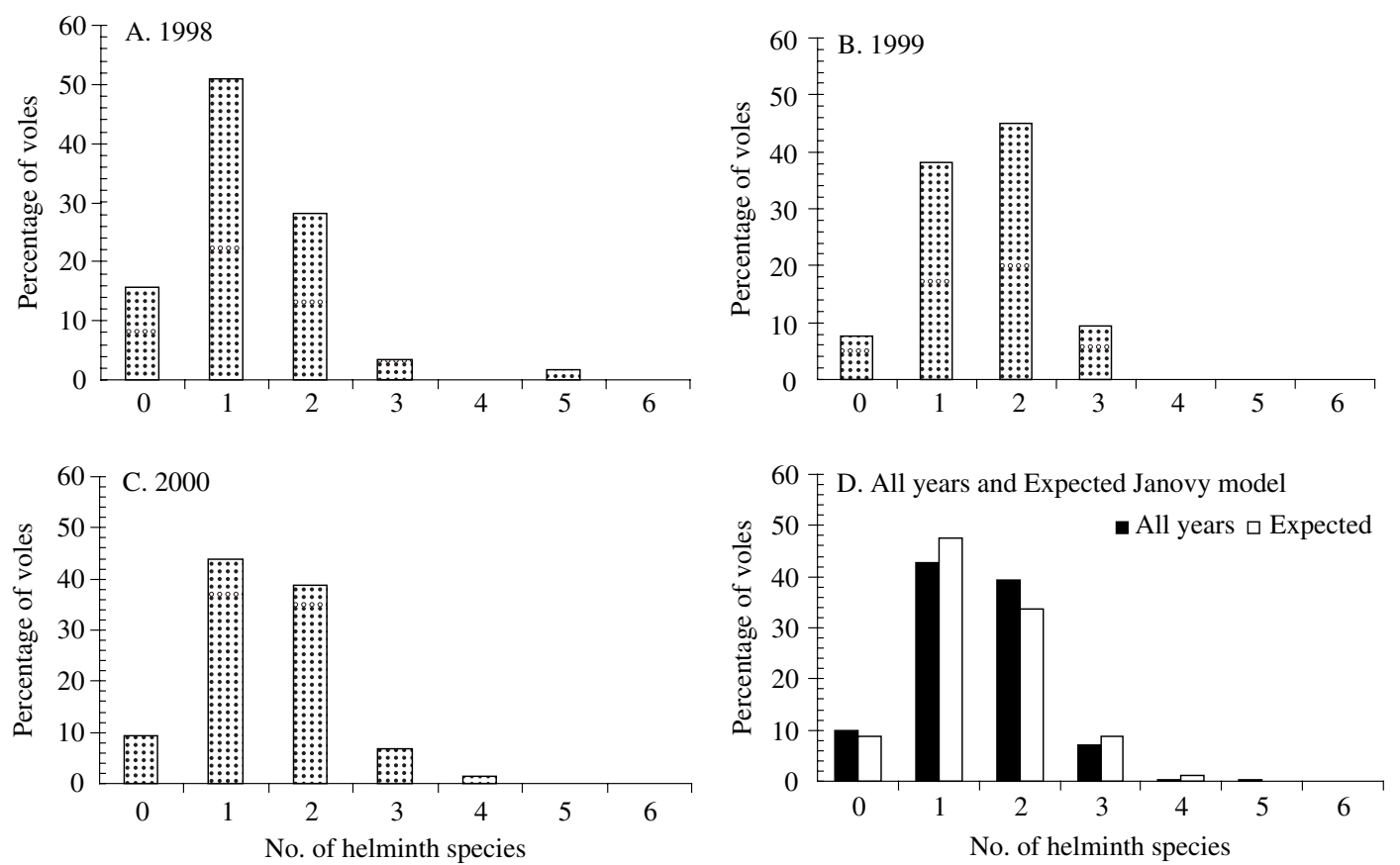

Fig. 3. Frequency distribution of infracommunity species richness in 1998 (A), 1999 (B), 2000 (C) and combined (D). In Fig. 4D the observed data are in the filled-in columns and those predicted by the null model of Janovy et al. (1995) in the open columns.

of $\operatorname{sex} F_{1,244}=0 \cdot 21, P=$ N.S.) and there were no other significant terms in this analysis.

\section{Species density distributions}

In each of the 3 years, the majority of animals carried 1 or 2 helminth species (Fig. 3, $1998-78.9 \%$, $1999-$ $83 \cdot 1 \%, 2000-82 \cdot 7 \%$ ). In all 3 years, some animals also carried three species (range $3 \cdot 9-9 \cdot 3 \%$ ), but only a single animal in 2000 carried 4 species and another in 1998, 5 species of helminths. These distributions differed significantly from both positive binomial and Poisson distributions, but could not be fitted to negative binomial models because of lack of degrees of freedom. The data from each year were combined (Fig. 3D) and compared to the distribution predicted by the null model for interactions of parasite species in an assemblage (Janovy et al. 1995). No significant difference was found $\left(\chi^{2}=4 \cdot 2\right.$, D.F. $\left.=4, P>0 \cdot 05\right)$.

\section{Prevalence of higher taxa}

The overall prevalence data are summarized by year of study in Table 3. At the highest taxonomic level (all helminths combined), there was little change between the years of the study. The minimum sufficient model (analysis by log-linear maximum likelihood) incorporated only two terms that included infection (presence/absence), season $\times$ age $\times$ infection $\left(\chi^{2}=8 \cdot 8\right.$, D.F. $\left.=2, P=0 \cdot 012\right)$ and season $\times \operatorname{sex} \times$ infection $\left(\chi^{2}=7 \cdot 7\right.$, D.F. $\left.=1, P=0.006\right)$. The former was essentially attributable to prevalence being lower in the over-wintering age class 3 voles in spring
$(77 \cdot 1 \%)$ compared with the autumn (95.9\%), and higher among juveniles (age class 1) in spring $(92.9 \%)$ compared with juveniles in the autumn $(81 \cdot 4 \%)$. The latter arose because female voles have a lower prevalence in spring $(73 \cdot 1 \%)$ compared with males $(91 \cdot 3 \%)$ and a higher prevalence $(94.9 \%)$ in the autumn ( males $=89 \cdot 2 \%$ ). A very similar pattern was found for nematodes, although the percentage values were marginally lower.

The only factor affecting the prevalence of cestode larvae was year of study $\left(\chi^{2}=6 \cdot 6\right.$, D.F. $\left.=2, P=0 \cdot 037\right)$. Prevalence varied from $1.8 \%$ in 1998 , through $11.0 \%$ in 1999 to $12 \cdot 0 \%$ in 2000 . In contrast, the prevalence of adult cestodes did not vary significantly between the years, although significant interactions of infection with sex and age $(3 \cdot 4,34 \cdot 0$ and $34 \cdot 8 \%$ in males and $18 \cdot 2,11 \cdot 6$ and $31 \cdot 6 \%$ in females of age classes 1 , 2 and 3 respectively, $\chi^{2}=9 \cdot 7$, D.F. $\left.=2, P=0 \cdot 008\right)$, year and age $(5 \cdot 6,27 \cdot 3$, and $25 \cdot 0 \%$ in $1998,4 \cdot 2,12 \cdot 5$ and $39 \cdot 1 \%$ in 1999 and $22 \cdot 6,38 \cdot 2$ and $30 \cdot 0 \%$ in 2000 in age classes 1,2 and 3 respectively, $\chi^{2}=10 \cdot 6$, D.F. $=4, P=0.03)$ and season $(40.8 \%$ in spring and $19.4 \%$ in autumn, $\chi^{2}=16 \cdot 8$, D.F. $\left.=1, P<0.0001\right)$ were found.

\section{Prevalence of species}

Prevalence of $H$. mixtum did not vary significantly between the years $(1998-78.9 \%, 1999-81.4 \%$, $2000-86 \cdot 7 \%$ ). However, as can be seen in Fig. 4A, prevalence was subject to a season $\times$ age interaction, being lower in the over-wintering age class 3 voles in spring compared with autumnal age class 3 voles, 

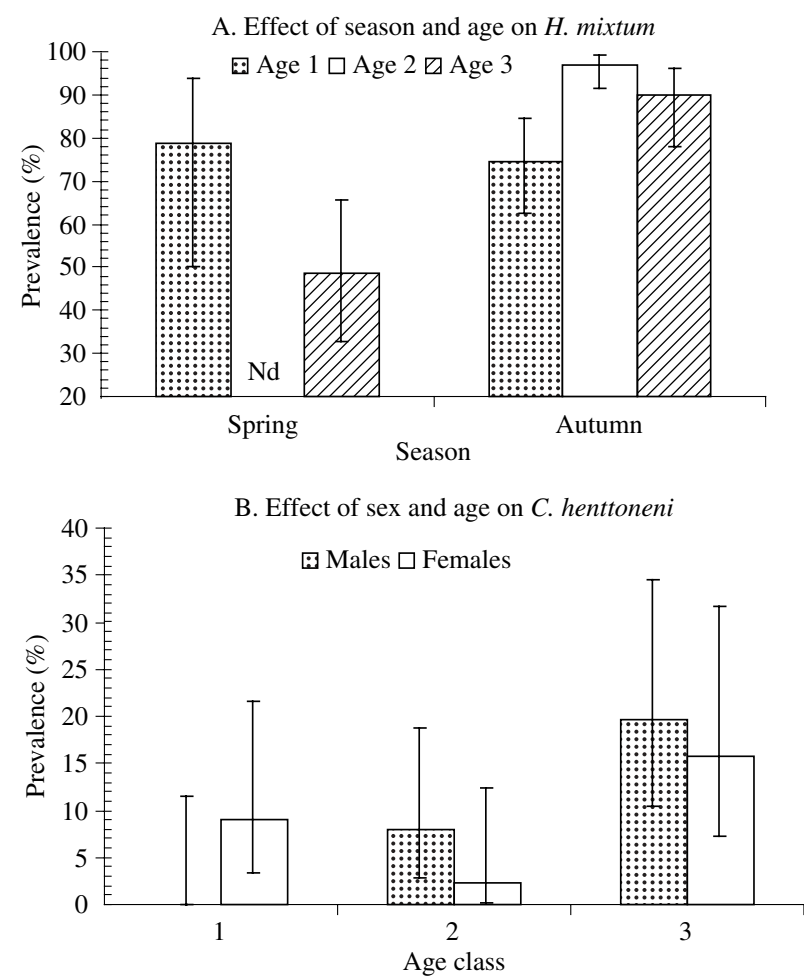

Fig. 4. Factors affecting the prevalence of Heligmosomum mixtum and Catenotaenia henttoneni. Error bars are $95 \%$ confidence limits. (A) Effect of age and season on H. mixtum. The only term incorporating infection in the minimum sufficient model was the age $\times$ season $\times$ infection interaction $\left(\chi^{2}=8 \cdot 01\right.$, D.F. $=2$, $P=0 \cdot 0182)$. (B) Effect of age and sex on C. henttoneni. For the interaction between sex $\times$ age $\times$ infection $\left(\chi^{2}=6 \cdot 5\right.$, D.F. $=2, P=0 \cdot 039$ ).

whereas in juvenile voles prevalence was very similar in both seasons.

The second most prevalent nematode, the oxyuroid $S$. petrusewiczi, showed significant variation between years (Fig. 5A), with prevalence varying from $13 \cdot 3 \%$ in 2000 to a peak of $41 \cdot 5 \%$ in 1999 . Infections with this species were twice as common in autumn compared with spring (Fig. 5B).

The cestode $C$. henttoneni was the third most prevalent species, and the prevalence of this species also varied between years although not as markedly as $S$. petrusewiczi (Fig. 5C), but the seasonal pattern was the reverse of $S$. petrusewicz $i$ with a prevalence of $26.5 \%$ in spring compared with only $5.5 \%$ in the autumn. $C$. henttoneni also showed an interesting age $\times$ sex interaction. Prevalence increased consistently in male voles from $0 \%$ in age class 1 to $19 \cdot 6 \%$ in age class 3 males, but in females prevalence was already high among juveniles, dropped among age class 2 voles and rose to a peak, as in males albeit lower, in age class 3 voles (Fig. 4B).

None of the remaining 13 species showed sufficiently high overall prevalence to facilitate analysis (Table 3). With the exception of $P$. omphalodes, all showed sporadic occurrence, being present in some years and not in others. P. omphalodes varied in prevalence from $1 \cdot 8$ in 1998 to $8.0 \%$ in 2000 .

\section{Frequency distributions and measures of aggregation}

Quantitative analysis was confined to the 3 species that showed an overall prevalence of approximately or exceeding $10 \%$. Analysis of the frequency distributions of the 3 species that met this criterion is shown in Table 5. It was not possible to test the distribution of $S$. petrusewiczi in 1998 for goodness of fit to the Poisson distribution because of insufficient degrees of freedom arising from too few animals carrying infection, in particular worm burden classes, and the Poisson and positive binomial distributions could not be rejected in the case of $C$. henttoneni in 1999 and 2000. Otherwise, the 3 species in all 3 years conformed to a negative binomial distribution as reflected in the values of the negative binomial aggregation constants, goodness of fit to the negative binomial distribution and the values of both $I$ and $D$.

\section{Abundance of infection}

The abundance of each species and higher taxa, by year and overall, is summarized in Table 6.

H. mixtum was analysed by 4 -way ANOVA in GLIM with negative binomial errors and the results are shown in Fig. 6. There was no significant variation in abundance between the years, but there were several interesting significant interactions. The abundance of infections was consistently higher in autumn compared with spring (Fig. 6A), but the extent of the difference varied between the years of the study. Similarly, in all 3 years abundance of infection was lowest in the juvenile voles, peaked in age class 2 and then dropped in the oldest age class 3 (Fig. $6 \mathrm{~B})$. In spring age class 2 voles are absent in local populations (the breeding season begins in March-April) and none were sampled in this study, the population comprising entirely of over-wintering adults (age class 3 ) and juveniles (age class 1). As Fig. 6C shows the abundance of infection with $H$. mixtum was similarly low in spring in juvenile and overwintering voles but 2-3 times higher in age class 2 and 3 voles sampled in autumn.

The abundance of $S$. petrusewiczi varied significantly between the years and, as with prevalence, 1999 was a peak year (Fig. 7A). Abundance was significantly higher in the autumn compared with spring, and analysis also revealed an interaction between sex and age (Fig. 7C) which was just outside significance but nevertheless suggested that whilst infections accumulate with age in males, abundance drops in the oldest age class in females.

Abundance of $C$. henttoneni varied only in relation to season (4-way ANOVA with normal errors on Log10 ( $\mathrm{x}+1)$ transformed data, main effect of season $\left.F_{1,249}=14 \cdot 32, P<0 \cdot 001\right)$. In spring the mean 
Table 5. Measures of aggregation for individual species of helminths by year

\begin{tabular}{|c|c|c|c|c|c|c|c|c|c|}
\hline \multirow[b]{2}{*}{ Species } & \multicolumn{3}{|l|}{1998} & \multicolumn{3}{|l|}{1999} & \multicolumn{3}{|l|}{2000} \\
\hline & $\begin{array}{l}k^{1} \\
\left( \pm \text { s.E.M. }{ }^{4}\right)\end{array}$ & $I^{2}$ & $D^{3}$ & $\begin{array}{l}k^{1} \\
\left( \pm \text { s.E.M. }{ }^{4}\right)\end{array}$ & $I^{2}$ & $D^{3}$ & $\begin{array}{l}k^{1} \\
\left( \pm \text { s.E.M. }{ }^{4}\right)\end{array}$ & $I^{2}$ & $D^{3}$ \\
\hline Heligmosomum mixtum & $\begin{array}{l}1 \cdot 038^{5,6} \\
(0 \cdot 074)\end{array}$ & $4 \cdot 74$ & $0 \cdot 544$ & $\begin{array}{l}1 \cdot 355^{5,6} \\
(0 \cdot 067)\end{array}$ & $3 \cdot 72$ & $0 \cdot 491$ & $\begin{array}{l}1 \cdot 416^{5,6} \\
(0 \cdot 105)\end{array}$ & $4 \cdot 68$ & $0 \cdot 501$ \\
\hline Syphacia petrusewiczi & $\begin{array}{l}0 \cdot 042^{5,7,8} \\
(0 \cdot 0001)\end{array}$ & $258 \cdot 2$ & $0 \cdot 901$ & $\begin{array}{r}0 \cdot 068^{5,6} \\
(0 \cdot 0001)\end{array}$ & $3287 \cdot 9$ & $0 \cdot 880$ & $\begin{array}{r}0 \cdot 021^{5,6} \\
(0 \cdot 0001)\end{array}$ & $424 \cdot 5$ & $0 \cdot 948$ \\
\hline Catenotaenia henttoneni & $\begin{array}{r}0 \cdot 096^{5,6} \\
(0 \cdot 0026)\end{array}$ & $3 \cdot 4$ & $0 \cdot 907$ & $\begin{array}{l}0 \cdot 199^{5,9} \\
(0 \cdot 035)\end{array}$ & $1 \cdot 33$ & 0.934 & $\begin{array}{l}0 \cdot 195^{5,9} \\
(0 \cdot 017)\end{array}$ & $1 \cdot 55$ & $0 \cdot 887$ \\
\hline
\end{tabular}

1 Negative binomial exponent.

${ }^{2}$ Index of dispersion $=$ Variance to mean ratio.

${ }^{3}$ Index of discrepancy (Poulin, 1993).

${ }^{4}$ Standard error of the mean estimate.

5 Not significantly different from negative binomial distribution.

6 Significantly different from positive binomial and Poisson distributions.

7 Significantly different from positive binomial.

8 Not possible to test for goodness of fit to Poisson distribution.

${ }^{9}$ Not significantly different from the positive binomial and Poisson distributions.
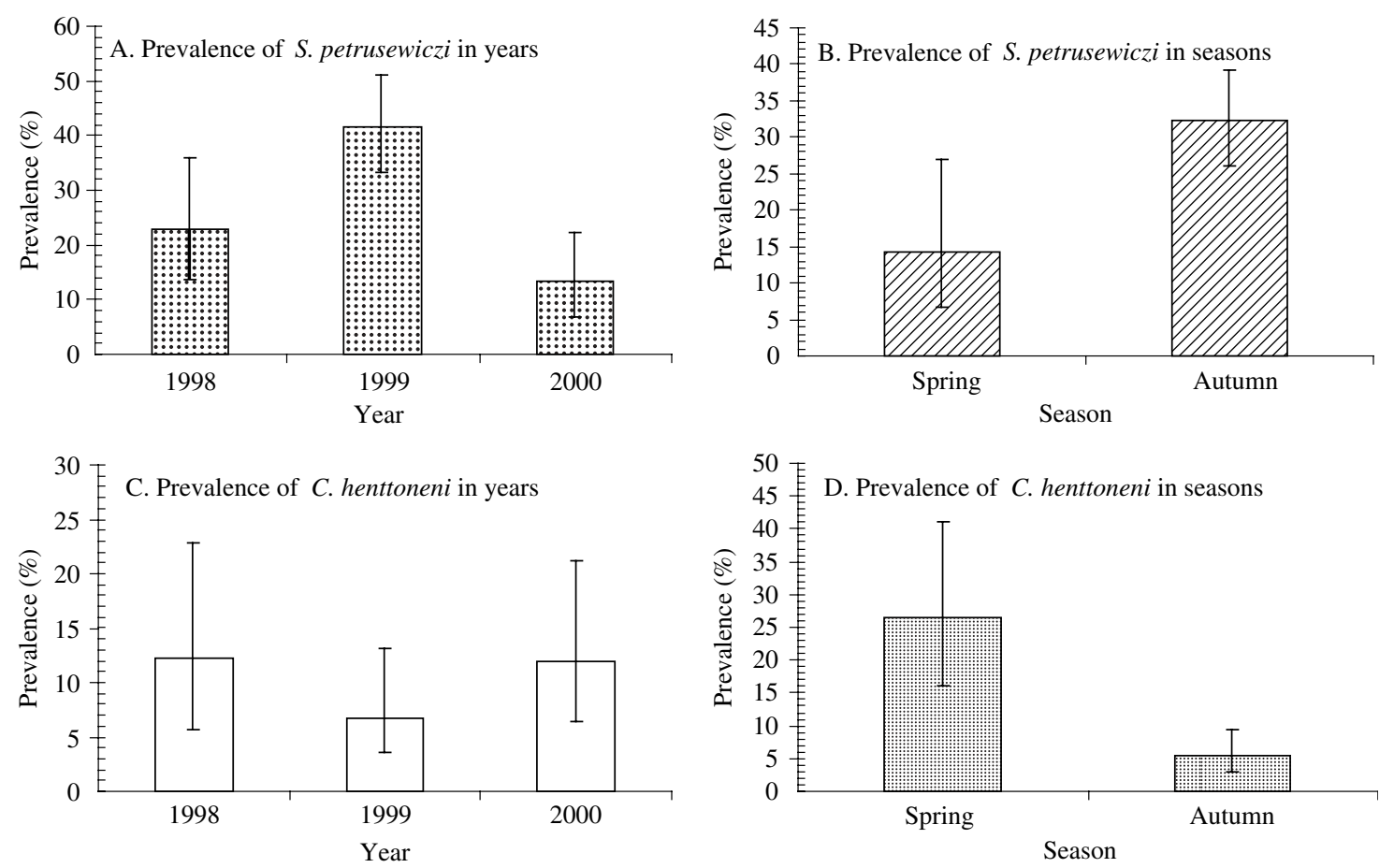

Fig. 5. Between year and seasonal variation in the prevalence of Syphacia petrusewiczi and Catenotaenia henttoneni. Error bars are $95 \%$ confidence limits. Effect of year $\left(\mathrm{A}, \chi^{2}=21 \cdot 6\right.$, D.F. $\left.=2, P<0 \cdot 0001\right)$ and season $\left(\mathrm{B}, \chi^{2}=8 \cdot 7\right.$, D.F. $=1$, $P=0 \cdot 003)$ on the prevalence of $S$. petrusewiczi. Effect of year $\left(\mathrm{C}, \chi^{2}=7 \cdot 8\right.$, D.F. $\left.=2, P=0 \cdot 020\right)$ and season $\left(\mathrm{D}, \chi^{2}=13 \cdot 0\right.$, D.F. $=1, P=0 \cdot 0003$ ) on the prevalence of $C$. henttoneni.

abundance $(\log 10$ units) was $0 \cdot 1 \pm 0 \cdot 025$ and in autumn $0 \cdot 02 \pm 0 \cdot 007$ (corresponding to back-transformed means of $0 \cdot 26$ and $0 \cdot 06$, respectively).

None of the remaining parasites were present in sufficient animals to merit analysis.

\section{DISCUSSION}

The key finding reported in this paper is the remarkable stability of the structure of helminth communities in bank voles in northeast Poland across the 3 years of the study. In spite of seasonal differences and strong age effects with respect to some of the indictors that we measured, the between-year effects were surprisingly minimal. Although they could not be tested statistically, measures of component community structure such as the BergerParker dominance index and the dominant species (S. petrusewiczi) did not vary or varied slightly from year to year. Similarly, the majority of measures of 
Table 6. The abundance of helminth taxa by year of study

\begin{tabular}{|c|c|c|c|c|c|}
\hline \multirow[b]{2}{*}{ Taxon } & \multirow[b]{2}{*}{ Species } & \multicolumn{3}{|c|}{ Mean \pm s.E.M. (maximum) for years } & \multirow[b]{2}{*}{ All years } \\
\hline & & 1998 & 1999 & 2000 & \\
\hline \multirow[t]{5}{*}{ Nematodes } & Heligmosomum mixtum & $3 \cdot 42 \pm 0 \cdot 53(21)$ & $4 \cdot 13 \pm 0 \cdot 36(19)$ & $3 \cdot 96 \pm 0 \cdot 50(24)$ & $3 \cdot 92 \pm 0 \cdot 26(24)$ \\
\hline & Syphacia petrusewiczi & $23 \cdot 05 \pm 10 \cdot 22(490)$ & $284 \cdot 75 \pm 89 \cdot 07(6130)$ & $18 \cdot 31 \pm 10 \cdot 18(577)$ & $145 \cdot 15 \pm 42 \cdot 94(6130)$ \\
\hline & Aspiculuris tetraptera & $0 \cdot 04 \pm 0 \cdot 02(1)$ & 0 & $0 \cdot 96 \pm 0 \cdot 58(42)$ & $0 \cdot 30 \pm 0 \cdot 18(42)$ \\
\hline & Heligmosomoides glareoli & 0 & $0 \cdot 03 \pm 0 \cdot 02(1)$ & $0 \cdot 03 \pm 0 \cdot 03(1)$ & $0 \cdot 02 \pm 0 \cdot 01(1)$ \\
\hline & Mastophorus muris & 0 & $0 \cdot 04 \pm 0 \cdot 03(2)$ & $0 \cdot 03 \pm 0.03(1)$ & $0 \cdot 03 \pm 0 \cdot 01(2)$ \\
\hline All nematodes & & $26 \cdot 51 \pm 10 \cdot 44(506)$ & $288 \cdot 95 \pm 89 \cdot 13(6134)$ & $23 \cdot 28 \pm 10 \cdot 19(583)$ & $149 \cdot 41 \pm 42 \cdot 97(6134)$ \\
\hline \multirow[t]{4}{*}{ Cestodes } & Catenotaenia henttoneni & $0 \cdot 28 \pm 0 \cdot 13(6)$ & $0 \cdot 08 \pm 0 \cdot 03(2)$ & $0 \cdot 19 \pm 0 \cdot 06(2)$ & $0 \cdot 16 \pm 0 \cdot 04(6)$ \\
\hline & Paranoplocephala omphalodes & $0 \cdot 02 \pm 0 \cdot 02(1)$ & $0 \cdot 06 \pm 0 \cdot 02(1)$ & $0 \cdot 09 \pm 0 \cdot 04(2)$ & $0 \cdot 06 \pm 0 \cdot 02(2)$ \\
\hline & Anoplocephaloides dentata & $0 \cdot 05 \pm 0 \cdot 04(2)$ & $0 \cdot 07 \pm 0 \cdot 04(4)$ & 0 & $0 \cdot 04 \pm 0 \cdot 02(4)$ \\
\hline & Rodentolepis assymetrica & 0 & $0 \cdot 008 \pm 0 \cdot 008$ & 0 & $0 \cdot 004 \pm 0 \cdot 004(1)$ \\
\hline \multirow[t]{6}{*}{ All adult cestodes } & & $0 \cdot 35 \pm 0 \cdot 13(6)$ & $0 \cdot 22 \pm 0 \cdot 06(4)$ & $0 \cdot 28 \pm 0 \cdot 07(3)$ & $0 \cdot 27 \pm 0 \cdot 05(6)$ \\
\hline & Taenia martis & 0 & $0 \cdot 03 \pm 0 \cdot 02(1)$ & $0 \cdot 12 \pm 0 \cdot 05(2)$ & $0 \cdot 05 \pm 0 \cdot 02(2)$ \\
\hline & Taenia mustelae & 0 & $0 \cdot 41 \pm 0 \cdot 29(29)$ & $0 \cdot 01 \pm 0 \cdot 01(1)$ & $0 \cdot 20 \pm 0 \cdot 14(29)$ \\
\hline & Taenia crassiceps & 0 & $0 \cdot 02 \pm 0 \cdot 01$ & 0 & $0 \cdot 008 \pm 0 \cdot 006(1)$ \\
\hline & Cladotaenia globifera & $1 \cdot 75 \pm 1 \cdot 75(100)$ & $0 \cdot 03 \pm 0 \cdot 02(2)$ & 0 & $0 \cdot 42 \pm 0 \cdot 40(100)$ \\
\hline & Mesocestoides sp. & 0 & $1 \cdot 03 \pm 0 \cdot 87(101)$ & $0 \cdot 20 \pm 0 \cdot 20(15)$ & $0 \cdot 55 \pm 0 \cdot 42(101)$ \\
\hline All larval cestodes & & $1 \cdot 75 \pm 1 \cdot 75(100)$ & $1 \cdot 53 \pm 0 \cdot 92(101)$ & $0 \cdot 33 \pm 0 \cdot 20(15)$ & $1 \cdot 22 \pm 0 \cdot 59(101)$ \\
\hline All cestodes & & $2 \cdot 11 \pm 1 \cdot 75(100)$ & $1 \cdot 75 \pm 0 \cdot 92(101)$ & $0 \cdot 61 \pm 0 \cdot 21(15)$ & $1 \cdot 49 \pm 0 \cdot 59(101)$ \\
\hline Digenea & Plagiorchis sp. & $0 \cdot 02 \pm 0 \cdot 02(1)$ & 0 & 0 & $0 \cdot 004 \pm 0 \cdot 004(1)$ \\
\hline \multicolumn{2}{|c|}{ All helminths (nematodes and cestodes combined) } & $28 \cdot 63 \pm 10 \cdot 55(506)$ & $290 \cdot 69 \pm 89 \cdot 19(0-6134)$ & $23 \cdot 89 \pm 10 \cdot 18(583)$ & $0 \cdot 90 \pm 43 \cdot 00(6134)$ \\
\hline
\end{tabular}

Abundance \pm S.E.M. (maximum worm burden; note that in all cases the lower limit was 0). 

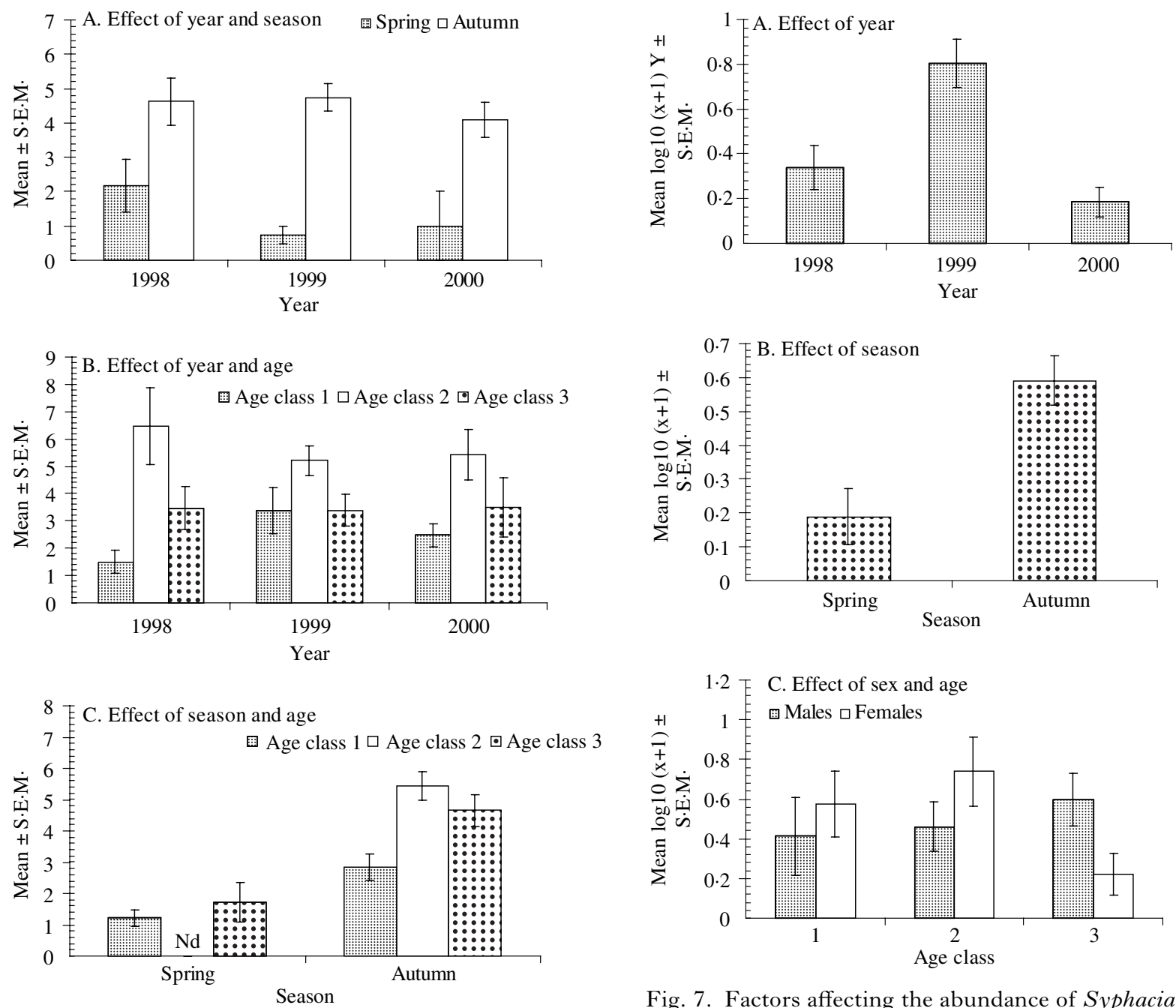

Fig. 6. Factors affecting the abundance of Heligmosomum mixtum. (A) Effect of year and season (4-way ANOVA in GLIM with negative binomial errors, 2-way interaction between year and season $\chi^{2}=7 \cdot 4$, D.F. $=2$,

$0 \cdot 025>P>0.01$; main effect of season $\chi^{2}=6 \cdot 17$, D.F. $=1$, $0.025>P>0.01$; main effect of year was not significant $\chi^{2}=2 \cdot 19$, D.F. $\left.=2\right)$. (B) Effect of year and age (2-way interaction between year and age $\chi^{2}=18 \cdot 6$, D.F. $=6$, $0 \cdot 005>P>0 \cdot 001$; main effect of age $\chi^{2}=27 \cdot 39$, D.F. $=2$, $P<0.0005)$. (C) Effect of season and age (2-way interaction between season and age $\chi^{2}=3 \cdot 61$, D.F. $=1$, $0 \cdot 075>P>0 \cdot 05)$.

variation at the infracommunity level were stable across the 3 years. Brillouin's index of diversity, prevalence of all helminths combined, prevalence and abundance of $H$. mixtum (the most prevalent helminth), and mean species richness all remained stable when other quantified parameters such as age, sex and seasonal variation had been taken into account.

Our conclusion that helminth communities in bank voles show stability in the medium-term concurs with and extends Kisielewska's (1970a) conclusions, which were not based on indices of diversity and similarity, nor underpinned by statistical analysis controlling for the confounding effects of

Fig. 7. Factors affecting the abundance of Syphacia petrusewiczi. (A) Effect of year (4-way ANOVA in GLIM with normal errors and $\log 10(\mathrm{x}+1)$ transformed data, main effect of year $F_{2,248}=11 \cdot 25, P<0 \cdot 001$ ). (B) Effect of season (main effect of season $F_{1,247}=8 \cdot 25$,

$0 \cdot 005>P>0 \cdot 001)$. (C) Effect of sex and age (2-way interaction between sex and age $F_{2,233}=2 \cdot 78$, $0 \cdot 1>P>0 \cdot 05)$.

other factors. In her studies on bank voles in Białowieża, she identified 4 out of 6 years as broadly showing comparable patterns and 2 as being quite distinct. Thus, in the longer-term, the medium-term stability may be temporarily perturbed, but exceptional years in Białowieża are infrequent and are followed rapidly by a return to the normal pattern (Kisielewska, 1970a). In cyclic bank vole populations in Finland, more marked changes were observed over 12 consecutive years, especially among the rarer species. Nevertheless, in years of medium to high vole density the dominant species $H$. mixtum and Catenotaenia sp. showed relatively stable prevalence (Haukisalmi et al. 1988). In contrast, helminth communities in Apodemus sylvaticus in south-east England varied significantly betweenyears over a 4 -year period. Although no clear cycles or patterns were identified, Behnke et al. (1999) reported that between-year variation, in conjunction 
with host age and to a lesser extent sex and their interactions, were the major causes of variation in helminth community structure in wood mice.

Some between-year variation was found in the current study, but even this was modest in comparison to seasonal and age differences. Significant between-year variation was mainly attributable to variation in the prevalence and exceptionally high abundance of the direct transmitted nematode $S$. petrusewiczi, with a peak in both parameters in 1999 . Not surprisingly therefore, at the component community level Simpson's index of diversity plunged low in 1999 and at the infracommunity level mean abundance of helminths (all species combined) was higher in 1999 than in 1998 and 2000. S. petrusewiczi, like many helminths of voles, has generated taxonomic confusion and has been subject to revision. This species was also identified by Kisielewska (1970 $a$; referred to as $S$. obvelata) as contributing to the atypical pattern of infections recorded in 1954, although otherwise infections were very comparable between-years, albeit prevalence was lower than in the current study. In $A$. sylvaticus in southeast England, the prevalence of S. stroma was higher at $56.7 \%$ and despite some variation in the mean worm burden and prevalence the differences between years were not significant (Behnke et al. 1999) indicating that medium-term stability may be a feature of infections with this member of the genus Syphacia.

Earlier workers besides Kisielewska (1970a) reported S. obvelata from bank voles (Furmaga, 1957; Sharpe, 1964; Ogden, 1971 ; Canning et al. 1973) but current opinion is that $S$. obvelata is strictly a parasite of Mus spp. (Hussey, 1957) and the corresponding Syphacia in bank voles is S. petrusewiczi (Tenora \& Meszaros, 1975; Wiger et al. 1978). Of all the helminths infecting wild rodents Syphacia spp. pose the greatest problems in quantitative studies. Syphacia spp. females migrate to the perianal surface and either release their eggs or rupture in so doing. However, these eggs are rapidly infective and autoinfection is frequent as voles clean their fur. For this reason worm burdens with this species show the greatest range and the greatest aggregation, and this can be so extreme as to prevent meaningful quantitative analysis. In this study 1999 was a year when $S$. petrusewicz $i$ worm burdens were very high and these affected other parameters such as Simpson's index of diversity. It is also of interest that 1999 was the year when we saw the highest population density of bank voles in the wood in the autumn, supporting the idea that prevalence of this species is linked to population density of bank voles, as noted by Kisielewska $(1970 a)$ in Białowieża National Park in Poland, Haukisalmi \& Henttonen (1990) in Finland and Lewis (1968) on S. stroma in wood mice in Wales.

Between-year variation was also detected in the prevalence of cestode larvae, with a marked increase in 1999 when the host population was at its highest, although prevalence was also high in the following year despite lower vole numbers during the autumn peak. Tenora et al. (1979) associated high prevalence of cestode larvae in bank voles with peak vole years and our data are consistent with this view, although longer-term studies are required in Poland to confirm the consistency of this association.

In contrast to between-year stability, helminth communities in bank voles showed predicted age effects and were subject to strong seasonal fluctuations. The importance of these two factors was first evident in the structure of the bank vole population itself. The spring population of voles is quite unique, comprising mainly over-wintering animals born in the preceding year, mostly at least 6 months old and diluted with just a few juveniles (age class 1) from the first cohorts born in mid-May. Distinctive helminth communities characterized the over-wintering voles with low prevalence and abundance of the most prevalent nematode $H$. mixtum, very low prevalence and abundance of $S$. petrusewiczi and relatively high prevalence and abundance of adult cestodes.

In this study we did not sample voles throughout the year, but rather intentionally confined sampling to two periods approximately 6 months apart: before and immediately after the onset of breeding in the spring, and towards the end of the breeding season in the autumn when almost all voles would have been from the current year. Breeding ceases in October and does not commence until March-April of the following year. In Białowieża, Kisielewska (1970a) identified November-January as a stable winter period during which only 4 species of helminthparasitized voles, February-March as a period of spring re-organization when insects emerge and pinworm infections re-appear, April-June as the second stage of the spring reorganization with appearance of additional helminths and newborn voles entering the host population, July-September as a period of summer stability in helminth burdens and growth of the host population and finally October as a period of autumnal crisis when helminth richness begins to fall. Seasonal changes in the helminth fauna of wild rodents are well documented also elsewhere in Europe (Lewis, 1968; Langley \& Fairley, 1982).

As expected, seasonal effects were detected in the present study but it is interesting how they differ from those observed in Western Europe. In our study most parameters (Brillouin's index of diversity, total helminth burden, H. mixtum (abundance and prevalence in age class 3 ) and $S$. petrusewiczi (prevalence and abundance), were higher in the autumn compared with the spring. Only $C$. henttoneni showed an opposite trend. In woodmice in the southeast of England, worm burdens are heaviest in the spring, as a result of accumulating worm burdens in non-breeding animals over the winter period ( $\mathrm{Abu}$ Madi et al. 2000), although summer peaks have also been recorded elsewhere in the UK (Lewis, 1968), 
Eire (Langley \& Fairley, 1982) and southern Norway (Tenora et al. 1979), followed by a drop in both prevalence and abundance as uninfected juveniles are recruited into the population in the summer breeding season. However, in bank voles in Poland we speculate that under the harsh winter conditions transmission of most helminths is less likely to occur than under the milder winter conditions in the UK. Hence loss of worms in over-wintering voles may result eventually in lower worm burdens in the spring. H. mixtum depend on free-living larval stages to complete their development to infective $\mathrm{L} 3 \mathrm{~s}$, and this phase of the life-cycle is almost certainly slowed, if not suspended entirely, during the subzero temperatures in the winter. A similar seasonal pattern to that found in Mazury was reported for bank voles in Finland infected with $H$. mixtum (Haukisalmi et al. 1988) and in Białowieża in eastern Poland (Kisielewska, 1970a).

Transmission of $S$. petrusewiczi is dependent on host contact (Lewis, 1968) and since the parasite has a short generation time and a short life-span transmission is likely to be less efficient during the winter because of restricted movement of hosts under winter conditions. The eggs of Syphacia spp. stick to host skin, and hence close contact between individuals encourages transmission. Reduction in both prevalence and abundance of infection with $S$. petrusewiczi during the winter period is consistent with Kisielewska's (1970a) findings that $S$. obvelata (probably $S$. petrusewiczi) disappeared from voles in late autumn through to spring. For both $H$. mixtum and $S$. petrusewiczi there is some evidence that worms are lost from older voles (see below) and the winter period would provide that opportunity in the absence of reinfection.

In contrast, infections with $C$. henttoneni were more prevalent in the spring ( 5 times higher) compared with the autumn, as reported also by Tenora $\&$ Zejda (1974) in the Czech Republic and Haukisalmi et al. (1988) in Finland. Kisielewska (1970a) suggested that the higher prevalence and abundance of C. pusilla (but probably C. henttoneni, see Haukislami \& Tenora, 1993) in the spring and early summer arose because the diet of bank voles at this time of the year was more dependent on animal rather than plant food (See also Hansson, 1985). C. henttoneni is probably transmitted by mites (Wardle \& McLeod, 1952), and these may survive under the cover of winter snow throughout winter and may be consumed by voles inadvertently with other invertebrates. Additionally, since like many other cestodes $C$. henttoneni probably causes chronic infections (see also below) worms are likely to accumulate over the winter period and in early spring. The decline over the summer period is probably a dilution effect with recruitment of juveniles to the host population and a lower transmission rate when plant and fungal items become more important in the diet (Kisielewska, 1970a; Tenora \& Zejda, 1974; Hansson, 1985; Haukisalmi \& Henttonen, 2000).

Long-lived helminth parasites are expected to accumulate with increasing host age (Behnke, 1987). Hence indices of diversity, richness, prevalence and abundance should all show some increase with age (Montgomery \& Montgomery, 1989). Mature and older voles (age class 2 and 3) showed higher Brillouin's diversity indices and higher mean species richness compared with juveniles, and significant age effects in the same direction were found for individual species such as $H$. mixtum (abundance), $S$. petrusewiczi (abundance), C. henttoneni (prevalence) and larval cestodes (prevalence). Interestingly, in both $H$. mixtum and $S$. petrusewiczi there was also evidence of a fall in abundance in the oldest age class. There was an indication (just outside significance) that abundance of $S$. petrusewiczi declined only among the oldest females, an observation with some similarity to the pattern found for $S$. stroma in woodmice (Behnke et al. 1999), where abundance was lower in females compared to males in all 3 age classes, but prevalence declined only in the oldest females, and to the data published by Kisielewska et al. (1973), Kisielewska (1971) and Kisielewska \& Zubczewska (1973) who observed declining burdens of S. obvelata (probably S. nigeriana, see Tenora \& Meszaros, 1975) among the oldest Microtus arvalis in their studies in Poland. Taken together, and considering the practical difficulty of establishing limits and criteria for age classes, these studies collectively support the idea that in Syphacia spp. reduction in prevalence and abundance among older hosts, and particularly females is a recurrent observation. In both Syphacia spp. and Heligmosomum and Heligmosomoides spp. these may reflect acquired immunity. Although neither species has been investigated in the laboratory, prolonged trickle exposure to the related heligmosomatid nematode Heligmosmoides polygyrus bakeri leads to resistance in some laboratory mouse strains (Behnke et al. 2003), and a similar pattern of declining abundance of H.p. polygyrus in older wood mice has been interpreted as indicating acquired immunity (Gregory, 1992; Gregory, Montgomery \& Montgomery, 1992). In $H$. mixtum this convex age-intensity profile was evident in all 3 years in the present study, which again reflects the relative medium-term stability of the helminth community across the period, despite the withinyear changes in relation to host age and strongly suggests that it was not a chance finding but a predictable phenomenon in this case.

However, in the same site in another of our studies conducted in August-September 1999, months when both prevalence and abundance of $H$. mixtum are known to peak in Poland (Kisielewska, 1970 $a$ ) and in a high vole density year, no significant age effect was detected for $H$. mixtum in bank voles. The youngest animals harboured the greatest burdens, which then 
declined in the two older age classes (Behnke et al. 2001). There is some evidence that in high density years infections are more prevalent in younger animals as naïve juveniles are rapidly recruited into the population and become infected (Haukisalmi \& Henttonen, 1990, 2000). Thus the age-intensity profile identified above varies, may be subject to seasonal variation and obscured in peak vole density years.

As in most studies of helminth communities of wild rodents (Kisielewska, 1970c; O'Sullivan et al. 1984; Abu-Madi et al. 2000, Behnke et al. 2001) we did not find a marked or a consistent influence of host sex (but see Ferrari et al. 2004). Both sexes were equally infected with the most prevalent helminth, $H$. mixtum, and there were no main effects of host sex on the abundance of $S$. petrusewiczi or $C$. henttoneni. Nevertheless, host sex was involved in some interactions with other factors. For example female voles showed about $20 \%$ lower prevalence of helminths (all species combined) in spring compared with males and $5 \%$ higher prevalence in the autumn. The spring difference might be the result of increased activity in males at the beginning of the reproductive season creating a greater opportunity to encounter the parasite infective stages, or a greater loss of overwintering worms by females. The prevalence of adult cestodes was affected by an interaction between host sex and age, but no clear pattern emerged.

The data presented in this paper show clearly that despite marked variation in parasite burdens and species composition between the two seasons (spring and autumn) within years, and predictable changes with respect to increasing host age, the overall patterns remained remarkably constant from one year to the next across the 3-year period of this study. This must indicate that the structure of the helminth community of $C$. glareolus in our study site in the seminatural managed forest of the Mazurian Landscape Reserve is relatively stable in the medium-term and supports the idea that transmission routes for the dominant helminths are well established. The sporadic occurrence at low prevalence of rare species of cestodes and the occasional digenean individually make little difference to the overall structure, which is largely maintained by the key roles played by the dominant gastrointestinal nematodes of bank voles and by the collective contribution of the rarer species. It will be interesting to monitor bank voles from this site over the longer-term and from neighbouring sites in the vicinity.

We are grateful to the British Council, UK and to the Polish Ministry of Scientific Research and Information Technology for providing partial financial support for this study (KBN grant 3P04C10225 and BC-KBN Joint Programme for Young Scientists WAR/342/06). We thank Professor M. Kozakiewicz (Head of the Department of Ecology, Institute of Zoology, University of Warszawa) and Mgr G.Gorecki, the director of the field station at Urwitalt for use of the facilities. We are grateful to
Professor Chris Barnard and Dr F. S. Gilbert for their comments on earlier versions of this manuscript. Finally we wish to acknowledge the support of the forestry department responsible for the woodland site utilized in our study (Nadleśnictwo Mikołajki).

\section{REFERENCES}

ABU-MADI, M. A., BEHNKE, J. M., LEWIS, J. W. \& GILBERT, F. S. (2000). Seasonal and site specific variation in the component community structure of intestinal helminths in Apodemus sylvaticus from three contrasting habitats in south-east England. Fournal of Helminthology 74, 7-15.

BAJER, A., PAWELCZYK, A., BEHNKE, J. M., GILBERT, F. S. \& SIŃski, E. (2001). Factors affecting the haemoparasitic component community structure in bank voles (Clethrionomys glareolus) from the Mazury lake district region of Poland. Parasitology 122, 43-54.

BEGON, M., HAZEL, S. M., BAXBY, D., BOWN, K., CAVANAGH, R., CHANTREy, J., JONEs, T. \& BENNETT, M. (1999).

Transmission dynamics of a zoonotic pathogen within and between wildlife host species.

Proceedings of the Royal Society of London, B 266, 1939-1945.

BEGON, M., HAZEL, S. M., TELFER, S., BOWN, K., CARSLAKE, D., CAVAnagh, R., CHANTrey, J., JONES, T. \& BENNETT, M. (2003). Rodents, cowpox virus and islands: densities, numbers and thresholds. Fournal of Animal Ecology 72, 343-355.

BEHNKE, J. M. (1987). Evasion of immunity by nematode parasites causing chronic infections. Advances in Parasitology 26, 1-70.

BEHNKE, J. M., BARNARD, C. J., BAJER, A., BRAY, D., DINMORE, J., FRAKE, K., OSMOND, J., RACE, T. \& SIŃSKI, E. (2001). Variation in the helminth community structure in bank voles (Clethrionomys glareolus) from three comparable localities in the Mazury Lake District region of Poland. Parasitology 123, 401-414.

BEHNKE, J. M., LEWIS, J. W., MOHD ZAIN, S. N. \& GILBERT, F. S. (1999). Helminth infections in Apodemus sylvaticus in southern England: interactive effects of host-age, sex and year on prevalence and abundance of infections. Fournal of Helminthology 73, 31-44.

BEHNKE, J. M., LOWE, A., CLIFFORD, S. \& WAKELIN, D. (2003). Cellular and serological responses in resistant and susceptible mice exposed to repeated infection with Heligmosomoides polygyrys bakeri. Parasite Immunology 25, 333-340.

BUSH, A. O., LAFFERTY, K. D., LOTZ, J. M. \& SHOSTAK, A. W. (1997). Parasitology meets ecology on its own terms: Margolis et al., revisited. Fournal of Parasitology 83, 575-583.

CANNING, E. U., COX, F. E. G., CROLL, N. A. \& LYONS, K. M. (1973). The natural history of Slapton Ley Nature Reserve: VI Studies on the parasites. Field Studies 3, 681-718.

CRAWLEY, M. T. (1993). GLIM for Ecologists. Blackwell Scientific Press, Oxford.

DASH, K. M., HALl, E. \& BARGER, I. A. (1988). The role of arithmetic and geometric mean worm egg counts in faecal egg count reduction tests and in monitoring strategic drenching programs in sheep. Australian Veterinary Fournal 65, 66-68. 
Elliott, J. M. (1977). Some Methods for the Statistical Analysis of Samples of Benthic Invertebrates. Freshwater Biological Association, Cumbria, UK.

ELTON, C., FORD, E. B., BAKER, J. R. \& GARDINER, A. D. (1931).

The health and parasites of a wild mouse population. Proceedings of the Zoological Society of London 1931, 657-721.

FERrari, N., CATtAdori, I. M., NESPEREIRA, J., RizZoli, A. \& HUDSON, P. J. (2004). The role of host sex in parasite dynamics: field experiments on the yellownecked mouse Apodemus flavicollis. Ecology Letters 7, 88-94.

FURMAGA, S. (1957). Helminthofauna gryzoni polnych (Rodentia) okolic Lublina. Acta Parasitologica Polonica 5, 9-50.

Genov, T. \& YAnchev, Y. (1981). Morphology and taxonomy of the nematodes of the genera Heligmosomoides Hall, 1916 and Heligmosomum Railliet et Henry, 1909 (Heligmosomidae Cram, 1927) from Bulgaria. Khelmintologiya 12, 8-30.

GREGORY, R. D. (1992). On the interpretation of hostparasite ecology: Heligmosomoides polygyrus (Nematoda) in wild wood mouse (Apodemus sylvaticus) populations. Fournal of Zoology 226, 109-121.

GREGORY, R. D., MONTGOMERY, S. S. J. \& MONTGOMERY, W. I. (1992). Population biology of Heligmosomoides polygyrus (Nematoda) in the wood mouse. Fournal of Animal Ecology 61, 749-757.

HANSSON, L. (1985). The food of bank voles, wood mice and yellow-necked mice. Symposia of the Zoological Society of London 55, 141-168.

Haukisalmi, v. \& HentTonen, H. (1990). The impact of climatic factors and host density on the long-term population dynamics of vole helminths. Oecologia $\mathbf{8 3}$, 309-315.

Haukisalmi, v. \& HentTonen, H. (1993). Coexistence in helminths of the bank vole Clethrionomys glareolus. I. Patterns of co-occurrence. Fournal of Animal Ecology 62, 221-229.

HaUkisalmi, v. \& HentTonen, H. (2000). The variability of helminth assemblages and populations in the bank vole Clethrionomys glareolus. Polish Fournal of Ecology 48 (Suppl.), 219-231.

HAUKisAlmi, V., HENTTONEN, H. \& TENORA, F. (1988). Population dynamics of common and rare helminths in cyclic vole populations. Fournal of Animal Ecology 57, $807-825$.

HAUKisAlmi, v. \& TENORA, F. (1993). Catenotaenia henttoneni sp.n. (Cestoda: Catenotaeniidae), a parasite of voles Clethrionomys glareolus and C. rutilus (Rodentia). Folia Parasitologica 40, 29-33.

HAZEL, S. M., BENNETT, M., CHANTREY, J., BOWN, K., CAVANAGH, R., JONES, T. R., BAXBY, D. \& BEGON, M. (2000). A longitudinal study of an endemic disease in its wildlife reservoir: cowpox and wild rodents. Epidemiology and Infection 124, 551-562.

HUSSEY, K. L. (1957). Syphacia muris vs S. obvelata in laboratory rats and mice. Fournal of Parasitology 43, 555-559.

JANOVY, J. Jr., CLOPTON, R. E., CLOPTON, D. A., SNYDER, S. D., EFTING, A. \& KREBS, L. (1995). Species density distributions as null models for ecologically significant interactions of parasite species in an assemblage. Ecological Modelling 77, 189-196.
KENNEDY, C. R. \& HARTVIGSEN, R. A. (2000). Richness and diversity of intestinal metazoan communities in brown trout Salmo trutta compared to those of eels Anguilla anguilla in their European heartlands. Parasitology 121, $55-64$.

KISIELEWSKA, K. $(1970 a)$. Ecological organization of intestinal helminth groupings in Clethrionomys glareolus (Schreb.) (Rodentia). 1. Structure and seasonal dynamics of helminth groupings in a host population in the Białowieza National Park. Acta Parasitologica Polonica 18, 121-147.

KISIELEWSKA, K. (1970b). Ecological organization of intestinal helminth groupings in Clethrionomys glareolus (Schreb.) (Rodentia). III. Structure of the helminth groupings in C. glareolus populations of various forest biocoenoses in Poland. Acta Parasitologica Polonica 18, 163-176.

KISIELEWSKA, K. $(1970 c)$. Ecological organization of intestinal helminth groupings in Clethrionomys glareolus (Schreb.) (Rodentia). IV. Spatial structure of a helminth grouping within the host population. Acta Parasitologica Polonica 18, 177-196.

KISIELEWSKA, K. (1971). Intestinal helminths as indicators of the age structure of Microtus arvalis Pallas, 1778 population. Bulletin de L'Academie Polonaise des Sciences. Serie des Sciences Biologiques Cl.II, 19, 275-282.

KISIELEWSKA, K., FRACZAK, K., KRASOWSKA, I. \& ZUBCZEWSKa, z. (1973). Structure of the intestinal helminthocoenosis in the population of Microtus arvalis Pallas, 1778, and the mechanisms of its variability. Acta Parasitiologica Polonica 21, 71-83.

KISIELEWSKA, K. \& ZUBCZEWSKA, Z. (1973). Intestinal helminths as indexes of reproduction dynamics in the host population - common vole. Acta Theriologica 18, 237-246.

KOZAKIEwicZ, M. (1976). The weight of eye lens as the proposed age indicator of the bank vole. Acta Theriologica 21, 314-316.

LANGLEY, R. \& FAIRLEY, J. S. (1982). Seasonal variations in infestations of parasites in a wood mouse Apodemus sylvaticus population in the west of Ireland. Fournal of Zoology 198, 249-261.

LEWIS, J. W. (1968). Studies on the helminth parasites of the long-tailed field mouse, Apodemus sylvaticus sylvaticus from Wales. Fournal of Zoology 154, 287-312.

MARGOLIS, L., ESCH, G. W., HOLMES, J. C., KURIS, A. M. \& SCHAD, G. A. (1982). The use of ecological terms in parasitology (report of an ad hoc committee of The American Society of Parasitologists). Fournal of Parasitology 68, 131-133.

montgomery, s. S. J. \& MONTgomery, W. I. (1988). Cyclic and non-cyclic dynamics in populations of the helminth parasites of wood mice Apodemus sylvaticus. Fournal of Helminthology 62, 78-90.

MONTGOMERY, S. S. J. \& MONTGOMERY, W. I. (1989). Spatial and temporal variation in the infracommunity structure of helminths of Apodemus sylvaticus (Rodentia:

Muridae). Parasitology 98, 145-150.

MONTGOMERY, S. S. J. \& MONTGOMERY, W. I. (1990). Structure, stability and species interactions in helminth communities of wood mice Apodemus sylvaticus. International fournal for Parasitology 20, 225-242. 
MORRIS, P. (1972). A review of mammalian age determination methods. Mammal Review 2, 69-104.

OGDEN, C. G. (1971). Observations in the systematics of nematodes belonging to the genus Syphacia Seurat, 1916. Bulletin of the British Museum (Natural History) Zoology 20, 254-280.

O'SUllivan, H. M., SMAL, C. M. \& FAIRLEY, J. S. (1984). A study of parasitic infestations in populations of small rodents (Apodemus sylvaticus and Clethrionomys glareolus) on Ross Island, Killarney. Fournal of Life Sciences of the Royal Dublin Society 5, 29-42.

POULIN, R. (1993). The disparity between observed and uniform distributions: a new look at parasite aggregation. International Fournal for Parasitology 23, 937-944

ROHLF, F. J. \& SOKAL, R. R. (1995). Statistical Tables.

Freeman W.H. and Company, San Francisco.

SHARPE, G. I. (1964). The helminth parasites of some small mammal communities. I. The parasites and their hosts. Parasitology 54, 145-154.

soŁTys, A. (1957). Badania nad robakami pasozytniczymi drobnych gryzoni Parku Narodowego w Białowieży. Acta Parasitologica Polonica 5, 487-504.

TENORA, F. (1967). Ecological study on helminths of small rodents of the Rohacska Dolina valley. Acta Scientiarum Naturalium Academiae Scientiarum Bohemoslovacae Brno 1, 163-207.

Tenora, F. \& Meszaros, F. (1975). Nematodes of the genus Syphacia Seurat, 1916 (Nematoda) - parasites of rodents (Rodentia) in Czechoslovakia and Hungary. Acta Universitatis Agriculturae 23, 537-554.
TENora, F. \& STANeK, M. (1995). Changes of the helminthofauna in several Muridae and Arvicolidae at Lednice in Moravia. II. Ecology. Acta Universitatis Agriculturae et Silviculturae Mendelianae Brunensis 43, $57-65$.

TENORA, F., WIGER, R. \& BARUs, v. (1979). Seasonal and annual variations in the prevalence of helminths in a cyclic population of Clethrionomys glareolus. Holarctic Ecology 2, 176-181.

TENORA, F. \& ZEJDA, J. (1974). The helminth synusy of Clethrionomys glareolus in a lowland forest and its changes. Acta Scientiarum Naturalium Academiae Scientiarum Bohemoslovacae, Brno 6, 1-48.

WARDLE, R. A. \& McLEOD, J. A. (1952). The Zoology of Tapeworms. The Univeristy of Minnesota Press, Minneapolis.

WASHington, H. G. (1984). Diversity, biotic and similarity indices. A review with special relevance to aquatic ecosystems. Water Research $\mathbf{1 8}$, 653-694.

WIGER, R., BARUS, V. \& TENORA, F. (1978). Scanning electron microscopic studies on four species of the genus Syphacia (Nematoda, Oxyuridae). Zoologica Scripta 7, 25-31.

Wilson, K. \& GRENFELl, B. T. (1997). Generalized linear modelling for parasitologists. Parasitology Today 13, 33-38.

ŻARNOWSKI, E. (1955). Parasitic worms of forest micromammalians (Rodentia and Insectivora) of the environment of Puławy (district Lublin) I. Cestoda. Acta Parasitologica Polonica 3, 279-343. 